\title{
POSISI R.S. QADR BERDASARKAN CORRESPONDENCE ANALYSIS PERSEPSI PASIEN DAN MANAJEMEN
}

\author{
Ns. Tatiana Siregar, S.Kep., MM \\ anna.regar@gmail.com.tatiana_siregar@yahoo.co.id
}

\begin{abstract}
Abstrak
R.S. QADR adalah rumah sakit swasta kelas C, yang memiliki 101 tempat tidur rawat inap, berlokasi di Karawaci Tangerang. Kondisi R.S. QADR teridentifikasi mempunyai permasalahan adanya penurunan kunjungan pasien rawat inap yang signifikan tiga tahun terakhir periode tahun 2009 - 2011. Penurunan jumlah pasien ini, diduga karena pelayanan yang diberikan kepada pasien kurang memuaskan, sehingga citra rumah sakit tidak terbentuk dengan baik dibenak pasien. Penelitian ini bertujuan: untuk mengetahui posisi R.S. QADR berdasarkan persepsi pasien dan manajemen. Metode penelitian yang digunakan observasional:deskritif komparatif, dan tehnik pengambilan sampel porposive sampling, denganjumlah 100 pasien rawat inap. Analisis penelitian secara deskritif dan correspondence analysis menggunakan ANACOR run syntax dari SPSS 19. Kesimpulan penelitian: menurut persepsi pasien, posisi R.S. QADR ditentukan oleh atribut: assurance, dan emphaty dari variabel kualitas pelayanan, sertaatribut tanggap dari variabel komunikasi teraupeutik. Tetapi posisi R.S. QADR berdasarkan persepsi manajemen ditentukan oleh atribut: responsiveness dari variabel kualitas pelayanan dan popular dari variabel citra rumah sakit. Perbedaan persepsi pasien dengan manajemen tentang atribut penentu posisi R.S. QADR, dikarenakan manajemen kurang memperhatikan dan menanggapi keinginan pasien. Untuk itu diharapkan pihak manajemen bisa lebih mengetahui lagi keinginan pasien dengan melalui survey pelanggan, agar kepuasan pasien terpenuhi.
\end{abstract}

Kata kunci: correspondence analysis, peta persepsi, atribut rumah sakit.

Abstract

The QADR Hospital is a class C private hospital, which has 101 inpatient beds, located in Karawaci, Tangerang. Implementation issues have been identified in the inpatient visits decreased significantly the last three years in the period 2009-2011. Decrease in the number of patients, it was assumed that the service provided to patients less than satisfactory, so that the image of the hospital is not well formed minds of patients. This research is aimed to determine the position of QADR Hospital based patient perception and management. Used observational research methods: a comparative descriptive, porposive sampling and sampling techniques, the number of 100 inpatients. Analysis of descriptive research and correspondence analysis using SPSS syntax Anacor run 19. Studies conclusion as perceived by the patient, the position of Qadr Hospital is determined by attributes: assurance, and empathy of service quality variables, well as attributes of the responsive variable therapeutic communication. But the position of Qadr Hospital is determined by management based on the perception of attributes: responsiveness of service quality variable and the popular of the hospital image variable. Differences in perception about the management of patients with QADR Hospital-positioning attribute, because the lack of management attention to and responding to the wishes of patients. It is expected to be know more the management of patients with longer desires through customer surveys, so the patient satisfaction of fulfilled.

Keywords: correspondence analysis, map perception, attribute hospital. 


\section{Pendahuluan}

Untuk mewujudkan derajat kesehatan seseorang dibutuhkan sumber daya di bidang kesehatan salah satunya adalah fasilitas pelayanan kesehatan. Salah satu fasilitas pelayanan kesehatan yang ada disekitar masyarakat adalah rumah sakit.Rumah sakit yang dimaksud tentunya adalah rumah sakit yang dapat memberikan pelayanan yang cepat, tepat,bermutu,ramah, dan terjangkau oleh masyarakat. Rumah sakit yang aman, cepat, tepat, bermutu, ramah dan terjangkau di kota besar seperti di wilayah Jakarta-Bogor-Depok-Tangerang-Bekasi menjadi suatu persaingan yang ketat dalam menyediakan jasa pelayanannya.

Salah satu rumah sakit yang peneliti lakukan observasi adalah R.S. QADR di wilayah Tangerang, yang memilki 101 tempat tidur, dan jumlah tenaga perawat 96 orang yang berdinas untuk rawat inap dan poli rawat jalan serta jumlah dokter yang terbatas, terutama dokter spesalis, yang hanya 4 orang yang sebagai karyawan tetap selebihnya adalah dokter yang diajak bekerja sama untuk praktek di poli rawat jalan. Tahun 2011, terjadi turn overtenagaperawat sebanyak 13 orang atau $13 \%$ dari 96 orang menjadi 92. Dari jumlah tenaga kesehatan yang kurang terutama perawat mengakibatkan kerja perawat overload dan komunikasi kepada pasien tidak teraupeutik sehingga kualita pelayanan atau jasa yang diberikan pada pasien kurang memuaskan bagi pasien, sehingga diasumsikan citra rumah sakit buruk dipersepsi pasien dan hal ini berdampak terhadap penurunan jumlah kunjungan pasien rawat inap maupun rawat jalan.

Data kunjungan terjadi penurunan yang signifikan terutama periodeantara 2009 2011 total pasien rawat inap berkurang dari 6.772 pasien (tahun 2009) menjadi 6.586 pasien (tahun 2010) atau terjadi penurunan 2,74\% (186 pasien), dan di tahun 2011 terjadi penurunan lagi sebesar $16,92 \%$ atau 1.115 pasien dengan total pasien hanya 5.471 pasien, sehingga penurunan jumlah pasien rawat inap ini mengakibatkan angka BOR(Bed Occupancy Ratio) hanya 59,3\% (lihat lampiran tabel data pasien RS. QADR).Selain itu penurunan kunjungan pasien juga diasumsikan karena banyaknya rumah sakit pesaing disekitar R.S. QADR. Berdasarakn latar belakang masalah yang dikemukakan diatas, maka dapat dirumuskan permasalahan : bagaimanakah psoisi R.S. QADR berdasrkan persepsi pasien dan manajemen?

\section{Tinjauan Pustaka}

\section{Kualitas Jasa}

Kualitas jasa adalah evaluasikognitif jangka panjang pelanggan terhadap hantaran jasa suatu perusahaan (Lavelock, 2007: 96).Menurut Gravin, dalamTjiptono(2011: 14) perspektif kualitas bisa diklasifikasikan dalam lima kelompok, yaitu: transcedental approach, product based approach, user-based approach, manufacturing-based approach, dan value-based approach.

Persepsi manajemen terhadap ekspektasipelanggan dalam membeli jasa dapat dilihat dari Model Kulitas Jasa, yang menyoroti kebutuhan utama untuk menghantarkan kualitas jasa yang tinggi (Kotler , $\mathrm{P}$ dan Keller, K.L, 2009: 399-400). Model ini mengidentifikasi lima kesenjangan yang menyebabkan kegagalan pengiriman jasa: 
a. Kesenjangan antara harapan konsumen dan persepsi manajemen. Manajemen tidak selalu mempunyai anggapan yang besar tentang apa yang diinginkan pelangan

b. Kesenjangan antara persepsi manajemen dan spesifikasi kualitas jasa - Manajemen mungkin mempunyai anggapan yang benar terhadap keinginan pelanggaan dan tetapi tidak menetapkan standar kinerja.

c. Kesenjangan antara spesifikasi kulitas jasa dan penghantaran jasa - Personal mungkin tidak terlatih, atau tidak mampu atau tidak bersedia memenuhi standar, atau mungkin terikat dengan standar yang bertentangan.

d. Kesenjangan antara penghantaran jasa dan komunikasi eksternal harapan konsumen dipengaruhi oleh pernyataan yang dibuat oleh iklan dan perwakilan perusahaan.

e. Kesenjangan antara jasa yang diharapkan - Jasa yang dirasakan Kesenjangan terjadi ketika konsumen salah menganggap kualitas jasa. Pelanggan mengharapkan pelayanan yang baik, ternyata kenyataannya tidak.

Berdasarkan lima kesenjangan ini para periset mengembangkan dasar penentu kualitas jasa yang terdiri dari 5 dimensi: keandalan (reliability), daya tanggap (responsiveness), Jaminan (assurance), Empati (empathy), dan Bukti fisik (tangible)Zeithaml (2003: $93-94)$.

\section{Komunikasi Terapeutik}

Inti pemasaran interaktif adalah komunikasi. Komunikasi bisa terjadi antara manajer dengan pelanggan, manajer dengan karyawan, dan karyawan dengan pelanggan. Komunikasi bukan hanya mempromosikan jasa baru dan mendorong orang untuk menggunakan jasa yang sudah tidak asing lagi bagi mereka. Lingkup kajian pemasaran interaktif yang berada di pelayanan jasa rumah sakit adalah komunikasi teraupeutik, dan pemasaran interaktif harus pula mempertimbangkan etika-moral yang kedua belah pihak saling menghormati dan mau menerima ide masing-masing mengatur hubungan hak dan kewajiban tenaga kesehatan.

Komunikasi terapeutik merupakan komunikasi profesional yang direncanakan secara sadar memiliki tujuan, dan kegiatannya dipusatkan untuk mengarah kepada kesembuhan pasien (Supriyanto, S., 2010: 252).

Komunikasi Teraupeutik: terjadi antara dokter atau perawat dengan pasien, sifat komunikasi lebih akrab karena memiliki tujuan dan fokus pada pasien yang membutuhkan bantuan, terjadinya komunikasi di rumah sakit, puskesmas, klinik atau praktik pribadi, dan direncanakan untuk mempercepat proses penyembuhan dan kepuasan pasien Supriyanto, S., 2010: 255)

Adapun tujuan komunikasi teraupeutik menurut Supriyanto, S (2010: 255-256) adalah:

a. Membantu pasien dalam memperbaiki dan mengendalikan emosi sehingga membantu mempercepat penyembuhan dari upaya medis.

b. Membantu pasien untuk memperjelas dan mengurangi 
beban perasaan dan pikiran serta dapat mengambil tindakan untuk mengubah situasi yang ada bila pasien percaya pada hal-hal yang diperlukan

c. Mengurangi keraguan, membantu dalam hal mengambil tindakan sefektif, dan mempertahankan kekuatan egonya.

d. Mempengaruhi orang lain, lingkungan fisik, dan dirinya.

e. Komunikasi teraupeutik memberikan pelayanan prima (service excellent atau tanpa cacat) sehingga dicapai kesembuhan dan kepuasan pasien.

f. Komunikasi yang menghasilkan kepuasan semua pihak yang terlibat (win win solution bagi dokter, perawat, dan pasien)

Menurut Supriyanto, S (2010: 256-260) dimensi komuniaksi terapeutik yaitu: attending skill, repect, tanggap (responsiveness), dan perhatian (emphaty). Stuart dan Sundeen (1995: 23 - 24) dimensi komuniaksi terapeutik adalah: responsif dan tindakan.

Hubungan komunikasi teraupeutik dengan kualitas pelayanan dinyatakan ada bukti yang kuat bahwa para profesional kesehatan perlu mempelajari ketrampilanketampilan dalam berkomunikasi untuk membentuk dan mempertahankan hubungan pelayanan yang berkualitas dengan pasien, jika kualitas pelayanan baik maka pelanggan akan puas.Ellis, R.B, et al (2000: 151). Kepuasan pelanggan rumah sakit atau kepuasan pasien dipengaruhi banyak faktor antara lain pendekatan dan perilakupetugas, mutu informasi, prosedur perjanjian, waktu tunggu, fasilitas umum yang tersedia, pengaturan kunjungan dan "privasi"outcome terapi, dan perawatan yang diterima dan salah satu faktor untuk mempengaruhi kepuasan pasien adalah pendekatan dan perilaku petugas yaitu komunikasi teraupeutik (Wijono, D, 1999)

\section{Citra Perusahaan}

Citra perusahaan yaitu: persepsi gambaran mental atau kesan dari sebuah organisasi yang ada dalam pikiran individu (Wilkinson, A, 1996)Citra perusahaan yang kuat akan mempengaruhi secara umum sikap dan perilaku konsumen terhadap organisasi dan secara khusus terhadap pembelian produk/jasa dari perusahaan, peyampaian yang positif word of mouth dari kinerja perusahaan (Suwandi, 2012). Buchari dalam Suwandi(2012) menegaskan bahwa citra dibentuk berdasarkan impresi, berdasarkan pengalaman yang dialami seseorang terhadap sesuatu sebagai pertimbangan untuk mengambil keputusan.

Perasaan puas atau tidaknya konsumen terjadi setelah mempunyai pengalaman dengan produk/jasa maupun perusahaan yang diawali adanya keputusan pembelian, sehingga dapat disimpulkan keberadaan citra perusahaan yang baik penting sebagai sumber daya internal obyek dalam menentukan hubugannya dengan perusahaan. Citra rumah sakit akan muncul setelah rumah sakit menjalankan kegiatannya atau melakukan pelayanannya, dan pelayanan ini dirasakan oleh pasien, dan penciptaan atau pemeliharaan citra rumah sakityang positif akan mendapatkankeuntungan kompetitif dalam industri pelayanan rumah 
sakit. Selanjutnya, hasil penelitian menunjukkan bahwa kualitas pelayanan merupakan kendaraan yang sangat efisien untuk meningkatkan kepuasan pasien, yang pada gilirannya meningkatkan loyalitas pasien (Wu, C.C, 2011)

Citra perusahaan terdiri dari empat elemen: personlity, reputation, value, dan corporate identity(Keller, K.L, 1998). Menurut Lamelas (2011) dimensi citra perusahaan meliputi: profesionalisme, moderen, melayani semua segmen masyarakat, perhatian (concern), dan popular. Menurut Davis dalam Lamelas (2011), dimensi citra perusahaan meliputi: agreeableness, enterprise, competenci, ruthlessness,chic, informality, dan machismo. Sedangkan menurut Slaughter dalam Lamelas(2011), dimensi citra perusahaan meliputi: boy scout, inovasi, dominan, thrift, dan style.

Hubungan kualitas pelayanan dengan citra perusahaan bisa disimpulkan bahwa kualitas pelayanan berpengaruh signifikan positif terhadap citra perusahaan (Ling, L.Y, 2011). Hasil penelitian menunjukkan bahwa kualitas pelayanan dan kepuasan pasien memainkan peran mediasi utama antara citra rumah sakit dan niat kunjungan kembali kerumah sakit (Wu, C.C., 2011)

4. Penempatan (Positioning) dan Peta Persepsi (Perceptual Map)

Salah satu aspek krusial dalam penyusunan rancangan jasa adalah positioning. Positioning adalah tindakan merancang penawaran dan citra perusahaan agar mendapatkan tempat khusus dalam pikiran pasar sasaran. Tujuannya adalah menempatkan merek dalam pikiran konsumen untuk memaksimalkan manfaat potensial bagi perusahaan.
Positioning merek yang baik membantu strategi pemasaran dengan cara memperjelas esensi merek, tujuan apa yang akan diraih pelanggan dengan bantuan merek dan bagaimana merek menjalankannya secara unik. Hasil positioning merek adalah terciptanya dengan sukses suatu proposisi nilai yang terfokus pada pelanggan (Kotler and Keller, 2009: 308 -309). Strategi penempatan (positioning) adalah strategi yang berusaha menciptakan keunikan (differensiasi yang unik) dalam benak pelanggan sasaran hingga terbentuk citra merek produk atau jasa yang lebih unggul dibandingkan merek produk atau jasa pesaing); dan kunci utama positionin gterletak padapersepsi yang diciptakan.

Persepsi adalah interpretasi seseorang terhadap rangasangan yang tidak nyata (intangible). Persepsi dipengaruhi oleh perannya terhadap yang dipersepsikan serta ditentukan oleh pengalamannya (Supriyanto, 2010: 109-110).

Untuk mengukur positioning digunakan teknikgrafis yang disebutperceptual mapping(peta persepsi), dibawah ini adalah beberapa pendapat tentang perceptual mapping.Peta persepsi adalah aplikasi Skala Multi Dimensional (MDS)dari berbagai tehnik seperti: Analisis Komponen Utama, Analisis Korespondensi, dan Analisis Diskriminasi. Data yang ditampilkan akan mencerminkan persepsi konsumen terhadap merek dalam pasar. Peta persepsi adalah tampilan grafis dimana merek yang digambarkan sedemikian rupa sehingga jarak antara merek mencerminkan perbedaaan mereka, dimana perbedaan diukur dari variabel yang dievaluasi. Variabel ini 
bisa berupa rank-orderings sampel yang disediakan kepada konsumen, atau sedetil set atribut dimana konsumen mengungkapkan hubungan mereka dengan merek, baik dalam bentuk indikasi merekatribut asosiasi atau rating skala pengukuran (Greencare,M., 2011).

\section{Metode Penelitian}

Penelitian ini pada dasarnya merupakan desain observasional: deskritif comparatif,yang hendak mengetahui penempatan rumah sakit pada map. Sesuai dengan konsep teori yang telah disampaikan pada tinjauan pustaka bahwa kualitas pelayanan, komunikasi terapeutik, citra rumah sakit mempengaruhi kepuasan dan loyalitas pasien. Dalam penelitian ini kualitas pelayanan, komunikasi terapeutik citra rumah sakit, masing-masing mempunyai dimensi atau atribut dan akan dilihat dari beberapa rumah sakit yang pernah dirasakan oleh pasien, sehingga memberikan informasi yang relatif lebih lengkap. Model penelitian yang peneliti susun untuk melihat persepsi pasien tentang atribut-atribut rumah sakit, sehingga menentukan posisi rumah sakit, bisa dilihat pada gambar di bawah ini:

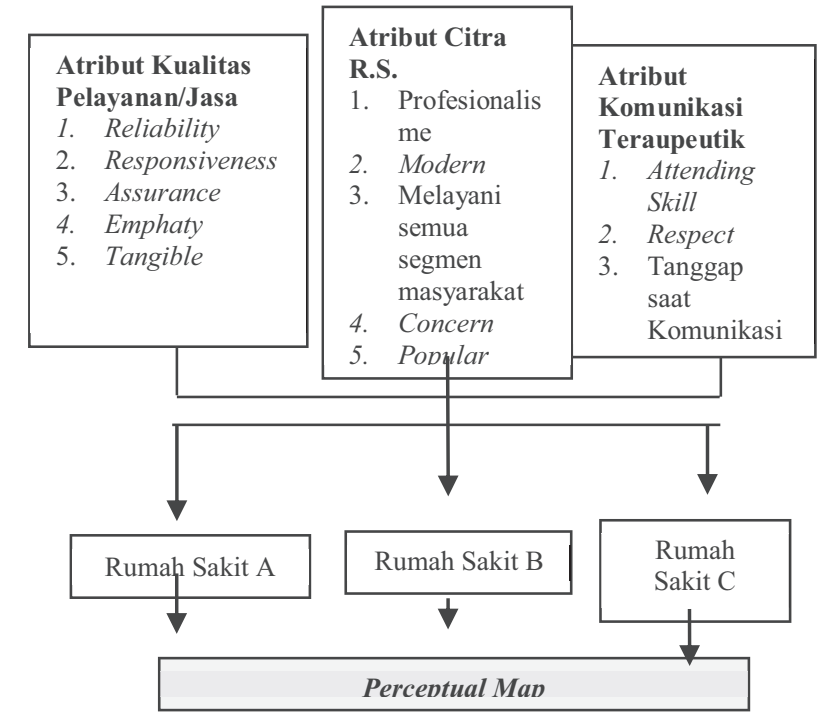

Sumber: Pribadi

Gambar 6. Model Penelitian
Tehnik pengambilan sampel dilakukan secara purposive sampling, dengan jumlah responden 100 pasien rawat inap dari 1.518 pasien selama periode rawat inap di RS. QADR pada bulan November - Desember 2012 atau $5.87 \%$ pasien yang digunakan sebagai sampel.

Penelitian ini menggunakan instrumen kuesioner sesuai dengan dimensi atau atribut dari setiap variabel dengan menggunakan skala Likert, 5 titik.Untuk variabel kualitas pelayanan ada lima atribut yaitu: reliability, assurance, emphaty, responsiveness, dan tangible. Atribut dari komunikasi terapeutik yaitu: attending skill, respect, tanggap, dan perhatian. Atribut citra rumah sakit: profesionalisme, alat moderen, melayani semua segmen masyarakat, concern (fokus pada pelanggan), dan popular. Setelah kusioner dijawab oleh pasien diolah dengan menggunakan analisis deskritif dan analisis koreponden

\section{Hasil dan Pembahasan}

Dari data demografi didapatkan informasi sebagai berikut: 95\% pelanggan yang menggunakan jasa rumah sakit adalah warga yang berdomisili di sekitar wilayah R.S. QADR, 41\% berpenghasilan rata-rata antara Rp. 1 Juta - Rp. 3 Juta, dan 50\% membayar jasa rumah sakit secara pribadi, 69\% pelanggan adalah baru pertama kali menggunakan jasa pelayanan R.S. QADR, $\quad 74 \%$ menyatakan mendapat informasi tentang R.S. QADR dari keluarga/teman; dan ada tiga rumah sakit pesaing dari R.S QADR yang pernah dirasakan oleh pasien saat ini Sumber: Pribadi

Gambar 6. Model Penelitian

yaitu: R.S. Siloam - Karawaci, R.S. Sari Asih - C Cimone dan R.S. Usada Insani - Cipondoh. 
Informasi data ini bisa digunakan oleh R.S. QADR untuk menarik pelanggan menjadi pelanggan yang loyal, karena $69 \%$ pelanggan adalah sebagai first time customer yang diharapkan mempunyai keterikatan tinggi bila pelanggan mempunyai preferensi yang kuat akan jasa yang ditawarkan oleh R.S. QADR dan dapat secara jelas membedakannya dari rumah sakit pesaing yang pernah responden rasakan, karena 50\% reponden adalah membayar secara pribadi, diharapkan setelah paska pembelian jasa R.S. QADR pelanggan tidak kecewa, sehingga pelanggan mempunyai dasar pertimbangan untuk tidak beralih ke rumah sakit pesaing.

Untuk pelanggan berulang (repeat customer) yang sebanyak 31\% diharapkan R.S. QADR bisa memberikan kepuasan kepada pelanggan agar yang $31 \%$ ini bisa menjadai advocator loyalty yaitu yang secara sukarela dan ekskusif merekomendasikan jasa R.S. QADR kepada teman, relasi, dan kelompok masyarakat lainnya.

Berdasarkan persepsi pasien, ada delapan atribut utama yang menentukan posisiposisi keempat rumah sakit, yaitu: reliability, assurance, emphaty,tangible, respect, tanggap, profesionalisme, dan alat moderen. Untuk posisi R.S. QADR ditentukan oleh atribut: assurance, emphaty dari variabel kualitas pelayanan, dan tanggap dari variabel komunikasi tarapeutik.

Jika berdasarkan persepsi manajemen, ada enam atribut utama yang menentukan keempat posisi rumah sakit, yaitu: responsiveness, emphaty, tangible, perhatian, alat moderen, dan popular. Tetapi untuk posisi R.S. QADR ditentukan oleh atribut: reponsiveness dan popular.
Posisi rumah sakit dan atribut-atribut rumah sakit bisa dilihat dalam gambar berikut:

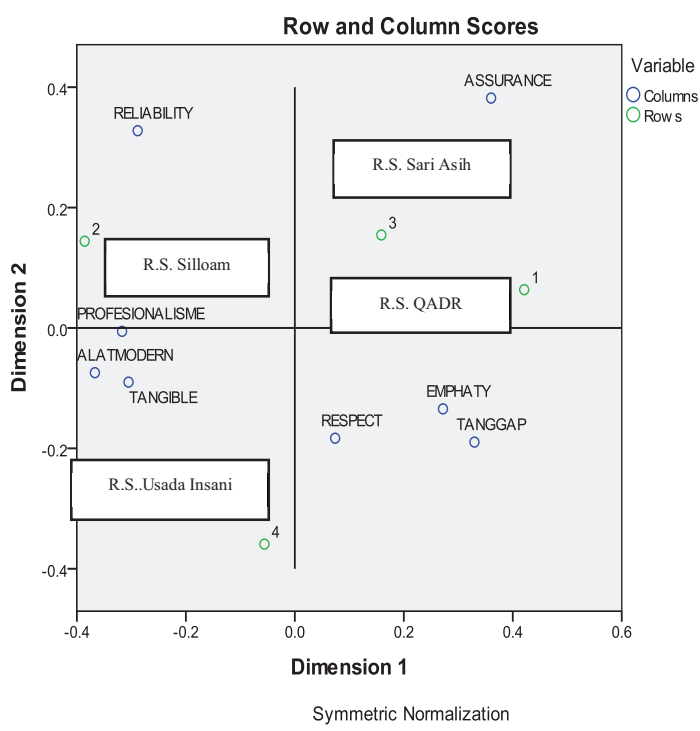

Gambar 1. Sebaran Atribut dan Posisi Rumah Sakit Berdasarkan Atribut Utama Persepsi Pasien



Gambar 2. Sebaran Atribut dan Posisi Rumah Sakit Berdasarkan Atribut Utama Persepsi Manajemen 


\section{Kesimpulan dan Saran}

Berdasarkan hasil analisa data dan pembahasan pada bab IV, maka dapat diambil kesimpulan bahwa jika ditinjau dari persepsi pasien, posisi R.S. QADR ditentukan oleh tiga atribut rumah sakit. Ketiga atribut tersebut dilihat dari jarak kedekatan pada titik perceptual map, atribut assurance adalah yang terdekat ke posisi R.S. QADR, diikuti atribut emphaty dan tanggap. Jika ditinjau dari persepsi manajemen, maka posisi R.S. QADR ditentukan oleh atribut responsiveness (dari variabel kualitas pelayanan), dan popular (dari variabel citra rumah sakit). Kesimpulan ini berbeda dengan persepsi pasien sebelumnya. Hal ini dikarenakan manajemen kurang meperhatikan dan menanggapi keinginan pasien, dan ini juga sudah diketahui oleh manajemen saat dilakukan dilakukan FGD.

Pihak manajemen beranggapan, bahwa hal ini lumrah karena ada perbedaan sudut pandang antara pasien dengan manajemen dalam menjawab kuesioner. Kesimpulan ini sejalan dengan penelitian yang dilakukan oleh Tweggie (2011), yang menyatakan ada perbedaan persepsi antara pasien dengan manajemen dan CEO R.S. Siloam dalam mempersepsikan atribut rumah sakit, dikarenakan manajemen kurang memperhatikan dan menanggapi saran dan keluhan pasien.

\section{Daftar Pustaka}

Arikunto, S. (2005). Manajemen Penelitian. Jakarta: Rineka Cipta

Bagozzi, R.P., et al. (1998) Marketing Management Upper Saddle River, NJ: Prentice Hall.

Balmer. J.M.T. (1995) 'Corporate Branding and Connoisseurship', Journal of General Management, 21 (1), pp.2446.
Baloglu, S. (2002). Dimensions of Customer Loyalty. European Journal

of Marketing. P: 1372-1388.

BAPPENAS. (2010). Laporan Pencapain Tujuan Pembangunan Milenium Indonesia

Blake, B.F ; et al. (2003). Perceptual Mapping by Multidimensional Scaling: A Step by Step. Candidate Methodology Series . Cleveland State UniversityEntire Series available:

http://academic.csuohio.edu

DEPKES (2005). Indikator Mutu Pelayanan Rumah Sakit

Doey, L and Kurta, J. (2011). Correspondence Analysis Applied to Psychological Research Tutorials in Quantitative Methods for Psychology. Vol. 7(1). P 5-14.

Dowling. (1993). Developing Your Company Image Into a Corporate Asset', Long RangePlanning, Jorurnal Busness Research Vol. 26.(2) P: 101- 109

Ellis, R.B., et al. (2000). Komunikasi Interpersonal Dalam KeperawatanTeori dan Praktik. Edisi Bahasa Indonesia. Jakarta: EGC

Fellenberg, K., et al. (2001). Correspondence Analysis Applied to Microarray Data Preceedings of the National Academy of Sciences. Vol: 98. P: 10781-10786.

Greencare,M. (2011).Dynamic Perceptual Mapping. Depaertermen of Economi and Business,Universitas Pompeu Fabra Ramon Trias Fargas Barcelona, Spain.

Griffin, J. (2005). Customer Loyality Menumbuhkan dan Mempertahankan Kesetiaan Pelanggan. Edisi Bahasa Indonesia 
Jakarta Erlangga

Gunawan, K. (2011).Kualitas Layanan dan Loyalitas Pasien. Jurnal Manajemen dan Kewirausahaan, Vol. 13, 1 Maret 2011

Guna, B.S. (2009). Pengukuran Tingkat Kepuasan Pelanggan: Untuk Menaikkan Pangsa Pasar. Jakarta: Koompas.

Hair, J.F., et al.(2010).Multivariate Data

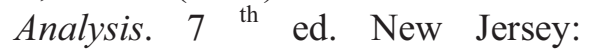
Pearson Education, Inc. P: 596 -597

Harrison, S. (1995). Marketers Guide To Public Relations. New York: John Willy and Son. . p: 71.

Hasan, S. (2008). Pengaruh Kualitas Layanan, Citra, Nilai dan Kepuasan Terhadap Loyalitas Pasien. Jurnal Aplikasi Manajemen. Vol. 8 No. 1Februari 2010

Hellina, T. (2011) . Tesis: Correspondence Analysis Persespi Pasien Dan Manajemen Terhadap Kualitas Jasa Pelayanan Siloam Hospital Kebon Jeruk. Jakarta. Jakarta: Universitas Esa Unggul

Hoffman, D. L.,et al. (1986). Correspondence Analysis: Graphical Representation of Categorical Data in Marketing Research. Journal of Marketing Research. Vol: 23. P: 213-227.

Javadi, M.H.M; et al.. (2012). Gaps of Service Quality in Private Banks Customers Regarding SERVQUAL in Isfahan, Iran. Journal of Sociological Research.Vol 3 (2)

Javalghi, R. (1992). Hospital Image: A Coreespondence Analysis Approach Journal Health Care Marketing Vol. 4. 12 Desember 1992. P: 34 -41

Keller, K.L. (2000) 'Building and managing corporate brand equity', pp.115-137 Oxford: Oxford University Press,.

(2008).Strategic Brand

Management Building,

Measuring, and

Managing BrandEquity, $3^{\text {rd }}$ ed.,

Prentice-Hall, Inc: New Jersey

Kotler, P dan Keller, K.L. (2009). Marketing Management. $13^{\text {th }} \mathrm{Ed}$.

New

Jersey: Pearson Prentice Hall

Laksono, I.N. (2008). Tesis : Analisis Kepuasan dan Hubungannnya dengan Loyalitas Pasien Rawat Inap di Rumah Sakit Dedi Jaya Kabupaten Brebes

Lamelas, M. (2011).Conceptualing and Measuring The Influence of CorporateImage on Country of Origin Image: The Case of Spain. Spanyol: Brunel Business Scholl,Brunel University.

Lavelock, C.H. dan Wright, L.K. (2007). Manajemen Pemasaran Jasa. Edisi

Bahasa Indonesia. Jakarta: Erlangga.

Lin, L.Y. (2011) The Influence of Service Quality, Cause-related

Marketing, Corporate Image on

Purchase Intention: The Moderating

Effects of Customer

Trust. International Journal of

Research in management Issuel,

Vol.3 (11)

Lombardo, R., et al.(2004). Simple and Multiple Ordered Correspondence Analysis to Evaluate Customer SatisfactionDisampaikan

ThirdAnnual ASEARC Conference 2 December 7-8 2009 Newcastle, Australia

Mc. Quail, D. and Sven, W. (1995). Communication Models for Study Mass Communication. London: Longman

Mundakir.(2006), Keperawatan Aplikasi dalam 
Pelayanan. Edisil. Jakarta. Grahallmu

PERMENKES: No.340/MENKES/PER III/2010: Klasifikasi RumahSakit

Santoso, S. (2011). Mastering SPSS Versi 19. Jakrta Elex Meda Komputindo

(2012).Statistik Multivariat: Konsep dan Aplikasi dengan SPSS. Jakarta Elex Media Komputindo

Sekaran, U. dan Buogie, R. (2010). Research Methods for Business: A Skill Building Approach. Ed: $5^{\text {th. }}$ United Kingdom: Jhon-Wiley \& Sons Ltd

Soemirat, S danArdianto,E. (2010). Dasasr-Dasar Public Relation. Bandung: Remaja Rosdakarya. Hal: $111-112$

Stanat, R. (2009) Brand Positioning And Perceptual Maps. www. branding strategy insider: The Black Project Research

Sten and Clausen, E. (1998). Series: Quantitative Applications in the Socia Sciences. London: Sage University Paper

Stuart, G.W. dan Sundeen, S.J. (1995). Buku Saku Keperawatan Jiwa. Edisi 3 (Bahasa Indonesia). Jakarta: EGC

Sugiyono (2012). Metode Penelitian Bisnis. Bandung: Alfabeta

Supranto. (2010). Analisa Multivariat Arti dan Interpretasi. Jakarta: Rineka Cipta

Supriyanto, S. dan Ernawaty. (2010). Pemasaran Industri Jasa Kesehatan Yogyakarta: Andi Offset

Suryani (2006) . Komunikasi Teraupeutik: Teori dan Praktik. Jakarta: EGC

Suwandi, I.M.D. Ebook: Seri Manajemen Pemasaran. Disadur dari www.wordpress.com. Juli 2012
Sunyoto. (2011). Analisis Regresi dan Hipotesis.Yogyakarta: CAPS

Tjiptono, F. (2000). Perspectif Manajemen dan Pemasaran Kontemporer.Yogyakarta: Andi Offset

Tjiptono, F. dan Chandra, G. (2005). Service, Quality dan Satisfaction. Ed. 3.Yogyakarta: Andi Offset

UU RI No. 36 tahun 2009: Tentang Kesehatan

Wijono, D. (1999) Manajemen Mutu Pelayanan Kesehatan, Teori dan Strategi dan Aplikasi. Vol.1. Surabaya: Airlangga.

Wilkinson, A. and Balmer, J.M.T. (1996) 'Corporate and Generic Identities: lessonsfrom the Co-perative Bank', International Journal of Bank Marketing, Vol.14 (4), pp.22-35.

Wijono, D. (1999) Manajemen Mutu Pelayanan Kesehatan, Teori dan Strategi dan Aplikasi. Vol.1. Surabaya: Airlangga.

Wilma and Verhallen, C.(1998). Nurseelderly Patient communication in Home Care andInstitutional Care. Journal Patient Education and Counseling.Vol 34 Netherlands Institue of Primary Health Care

Wu, C.C. (2011).The Impact of Hospital Brand Image on Service Quality, Patient Satisfaction and Loyalty.African Journal of Business management Vol. 5(12), P.. 48734882,18 June, 2011

Zeithaml and Bitner. (2003). Service Marketing.Integrating Customer Focus

Across The Firm. New York: The Mc Graw Hill Companies Inc 